Konjenital lateral eksikliğinin ortodontik tedavi sonrası hemen yüklenen implant ile tedavisi: Olgu sunumu

\section{Managing congenitally missing maxillary lateral incisor with immediate loaded single-tooth implant after orthodontic treatment: A case report}

\author{
Dr. Mücahide Akoğlan \\ Cukurova Üniversitesi Diș Hekimliği Fakültesi, \\ Protetik Diş Tedavisi A. D., Adana
}

Doç. Dr. Mehmet Emre Benlidayı

Cukurova Üniversitesi Dis Hekimliği Fakültesi, Ảğız, Diş ve Çene Cerrahisi A. D., Adana

Doç. Dr. Ufuk Tatlı

Cukurova Üniversitesi Dis Hekimliği Fakültesi, Ảğız, Diş ve Çene Cerrahisi A. D., Adana

Geliş Tarihi: 10 Ağustos 2016

Kabul Tarihi: 29 Ağustos 2016

DOI: 10.5505/yeditepe.2016.20592

\section{Yazısma Adresi:}

Dr. Mücahide Akoğlan

Cukurova Üniversitesi Diş Hekimliği Fakültesi, Protetik Diş Tedavisi A. D., Adana TÜRKIYE Tel: 03223386060

E-posta: mucahideakoglan@yahoo.com
ÖZET

Bu vaka raporunun amacı, konjenital maksiller lateral diş eksikliği olan hastanın multidisipliner tedavi yaklaşımı ile tedavisinin sunulmasıdır. Yirmi yaşındaki erkek hastanın ağız içi muayenesinde komşu kanin dişin konjenital maksiller lateral diş eksikliği boşluğuna doğru hareket ettiği belirlendi. Yeterli mesiodistal mesafe ortodontik tedaviyle hazırlandı ve bölgeye bir adet dental implant yerleştirildi. Uygun bir kapanış ilişkisi ve estetik bir görünüme ulaşmak için implant geçici kron ile hemen yüklendi. Üç aylık osseointegrasyon ve yumuşak doku şekillenmesini takiben daimi restorasyon yapılarak hastanın tedavisi tamamlandı.

Anahtar kelimeler: Konjenital diş eksikliği, ön bölge estetiği, hemen yükleme.

\section{SUMMARY}

The aim of this case report is to present the multidisciplinary treatment of a patient with congenitally missing maxillary lateral incisor. In the intraoral examination of a 20 years old male patient, it was determined that neighbor canine was migrated to the place of the congenital missing maxillary lateral incisor. Sufficient mesiodistal space was prepared by orthodontic treatment and a dental implant was placed surgically. To achieve a stable occlusion and aesthetic appearance, the implant was loaded immediately with temporary crown. Final restoration was completed three months after osseointegration and soft tissue regeneration.

Key words: Congenitally missing teeth, anterior aesthetic, immediate loading.

\section{Giriş}

Konjenital diş eksiklikleri çeşitli şekillerde tedavi edilebilir. Ideal tedavi doğal dişlere zarar vermeden, estetik beklentilerin karşılandığı tedavidir. İmplant tedavisi konjenital diş eksikliklerinde başarı ile uygulanabilir. Ancak çoğu olguda, eksik dişin yerine komşu diş hareket ettiği için implant yerleştirilecek yeterli alan bulunmaz. Bu gibi durumlarda, estetik olarak başarılı bir implant tedavisinin interdisipliner bir yaklaşımla planlanması gerekir. ${ }^{1,2}$ Dişlerin ortodontik yöntemlerle ideal konumlarına getirilmesi hem daha koruyucu hem de daha estetik sonuçlar vermektedir.3 Ortodontik tedavi ile final restorasyonun boyutlarına uygun olarak yeterli yer sağlanmasının ardından implant tedavisi gerçekleştirilir.

Estetik bölgede implantüstü protezlerdeki en büyük problem pembe estetiğinin sağlanamamasıdır. Bunun başlıca sebebi alveolar kemik ve yumuşak doku kaybıdır. Yumuşak doku kaybı cerrahi öncesinde gerçekleşmiş olabileceği gibi yapılan geniş flap dizaynına bağlı olarak cerrahi sonrasında da gelişebilmektedir. Final restorasyonda uygun yumuşak doku estetiğinin sağlanabilmesi için cerrahi işlem sırasında papil koruyucu midkrestal bir insizyon tercih edilebilir. Minimal invaziv bu yöntemle yumuşak doku ve papilla kaybının 
azaltılması amaçlanmaktadır. ${ }^{4}$

Implant tedavilerinde hemen yükleme kavramı yeterli primer stabilitenin sağlandığı durumlarda hastaya biran önce fonksiyon ve estetiğin kazandırımasını amaçlar. Ayrıca estetik bölgede geçici bir restorasyon ile implantın hemen yüklenmesi hastanın o anki estetik beklentilerini karşılamakla kalmaz iyileşme döneminde yumuşak doku şekillendirmesi sağlaması ile de final restorasyonun estetiğine katkıda bulunur. Hemen yükleme hastanın estetik ve fonksiyon beklentilerini karşıladığı gibi ikinci aşama cerrahinin elimine edilmesi ve tedavi süresinin kısalması gibi avantajlarından dolayı implant tedavisinin kabul edilebilirliğini arttırmaktadır. ${ }^{5}$

Bu olgu sunumunda, konjenital tek taraflı maksiller lateral diş eksikliği olan hastanın ortodontik tedavi sonrası hemen yüklenen implant ile tedavisi anlatılmaktadır.

\section{OLGU}

Konjenital tek taraflı sol maxiller lateral diş eksikliği olan 20 yaşında erkek hastanın klinik muayenesinde komşu kanin dişin eksik lateral diş bölgesine sürdüğü görüldü (Resim 1).

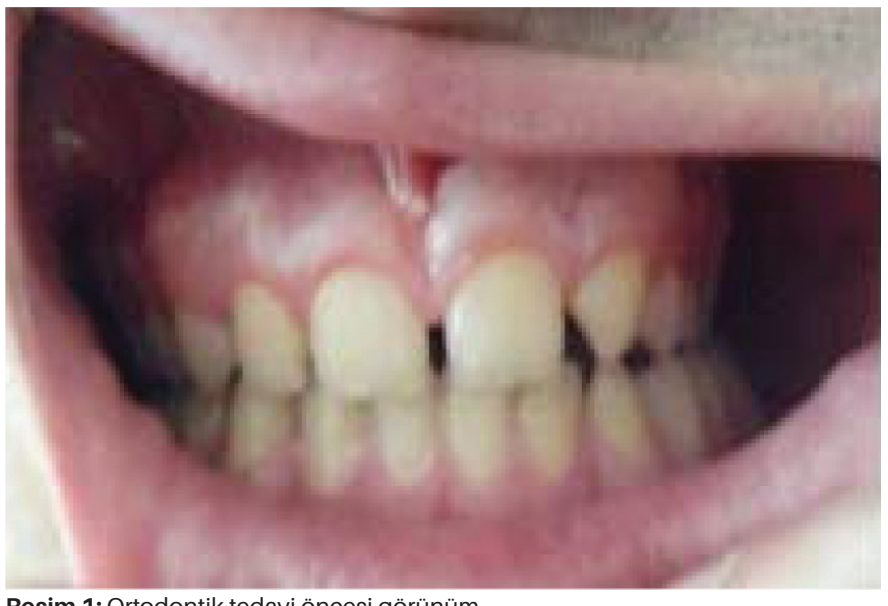

Resim 1: Ortodontik tedavi öncesi görünüm

Ortodontik tedavi ile yer kazanılmasının ardından implant yerleştirilmesine karar verildi (Resim 2).

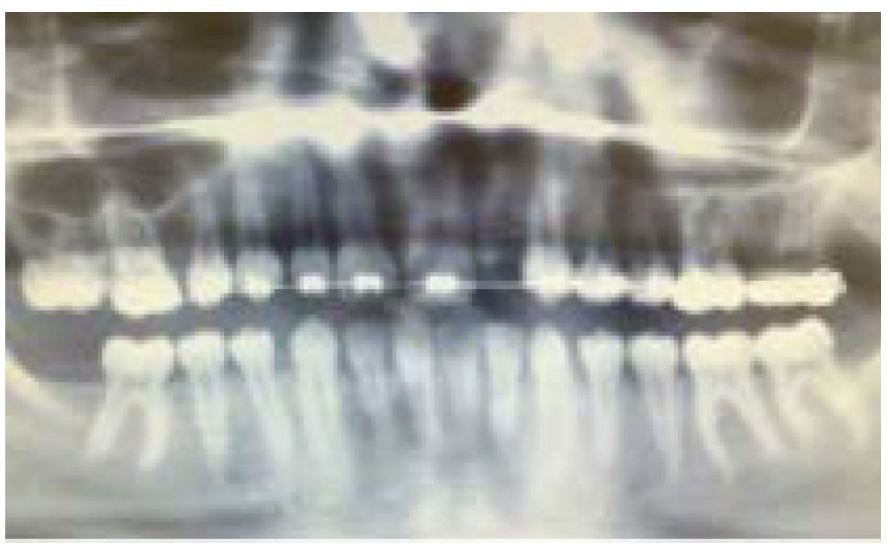

Resim 2: Ortodontik tedavi sonrası panoramik görüntü

18 aylık bir ortodontik tedavinin ardından yeterli yer kazanılarak implant tedavisine geçildi. Papil koruyucu midkrestal insizyon ile flep kaldırılarak implant yerleştirildi
(Dentium, implantium, Güney Kore) (Resim 3,4).

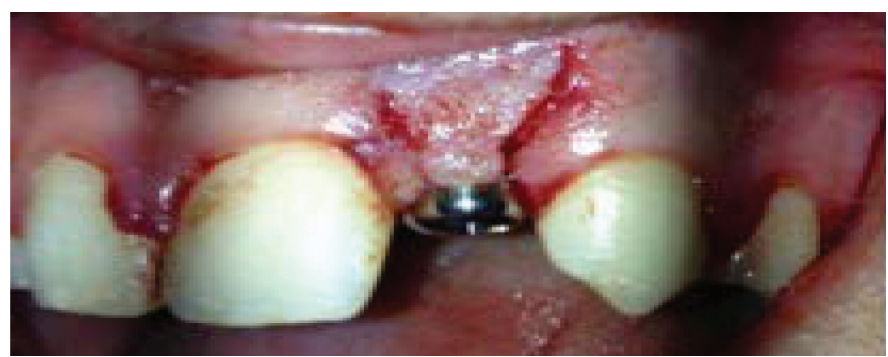

Resim 3: Papil koruyucu insizyon ve iyileşme başlığı

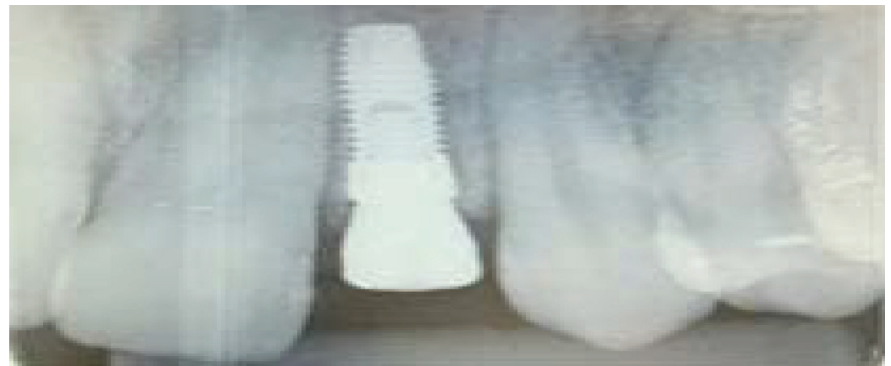

Resim 4: İmplantın radyolojik görüntüsü

Hastanın estetik beklentilerini karşılamak için ve yeterli primer stabilite elde edilmesiyle implantın hemen yüklenmesine karar verildi. Implantın primer stabilitesi manuel yerleştirme torku ölçülerek $(35 \mathrm{Ncm})$ ve rezonans frekans analizi cihazı ile dijital olarak belirlendi (ISQ:75). Hemen yükleme ilk bir hafta içerisinde vidalı akrilik bir geçici kron ile yapıldı (Resim 5).

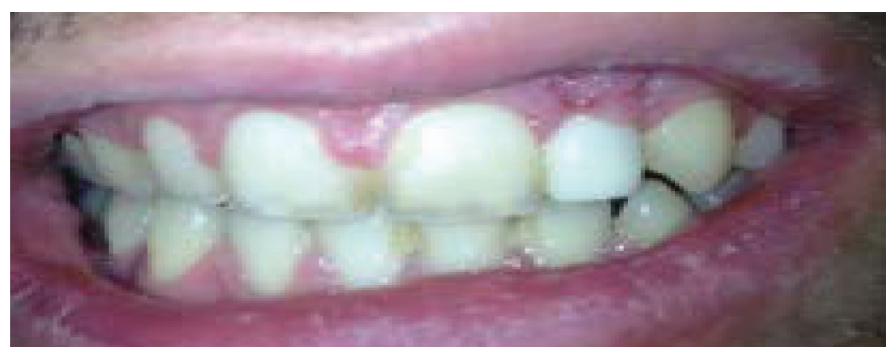

Resim 5: Vidalı akrilik geçici kron

Oklüzyon protrüziv ve lateral hareketlerde temasın kaldırılması şeklinde ayarlandı. Yapılan rutin kontrollerle yumuşak dokunun şekillenmesi sağlandı (Resim 6 $a, b)$. Üç ayın sonunda daimi metal-seramik restorasyon işlemlerine geçildi. Ölçü postu yerleştirilerek kapalı kaşık tekniği ile silikon ölçü maddesi kullanılarak implantın ölçüsü alındı (Panasil, Kettenbach, Eschenburg, Almanya). Laboratuvar işlemlerinin ardından restorasyon tamamlandı (Resim 6-9).

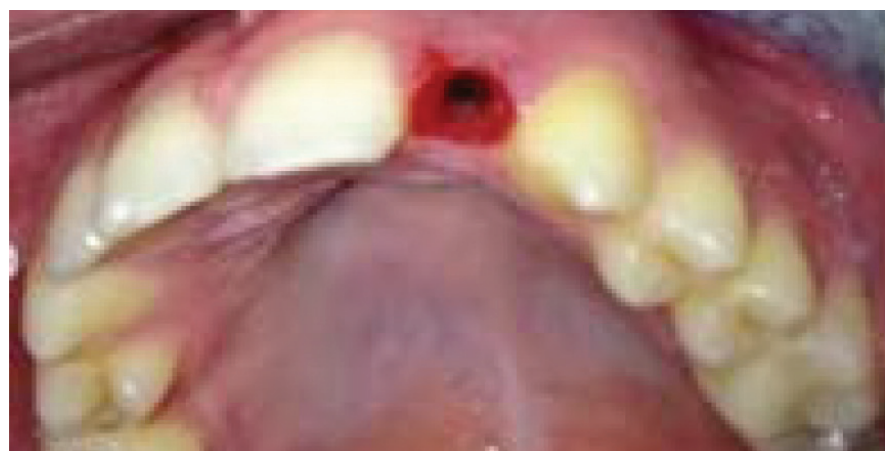

Resim 6 a: Şekillenen yumuşak doku görüntüsü 


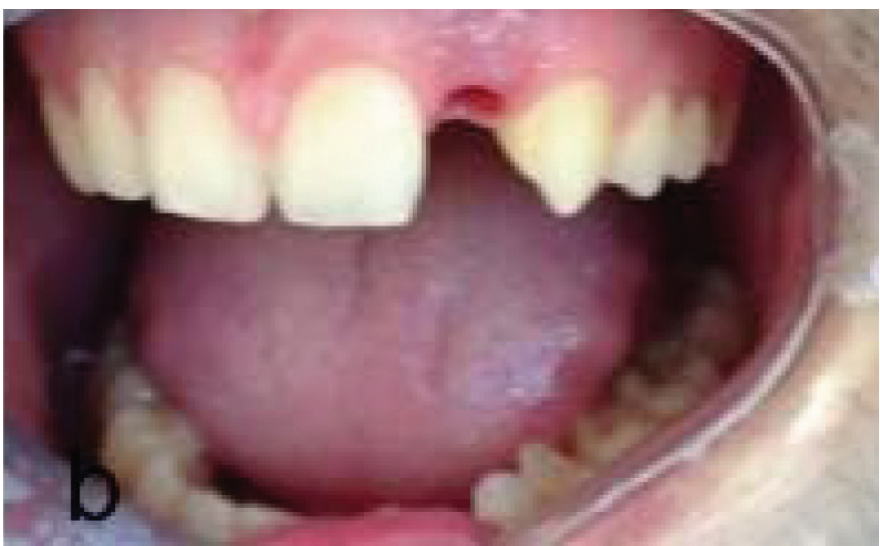

Resim 6 b: Şekillenen yumuşak doku görüntüsü

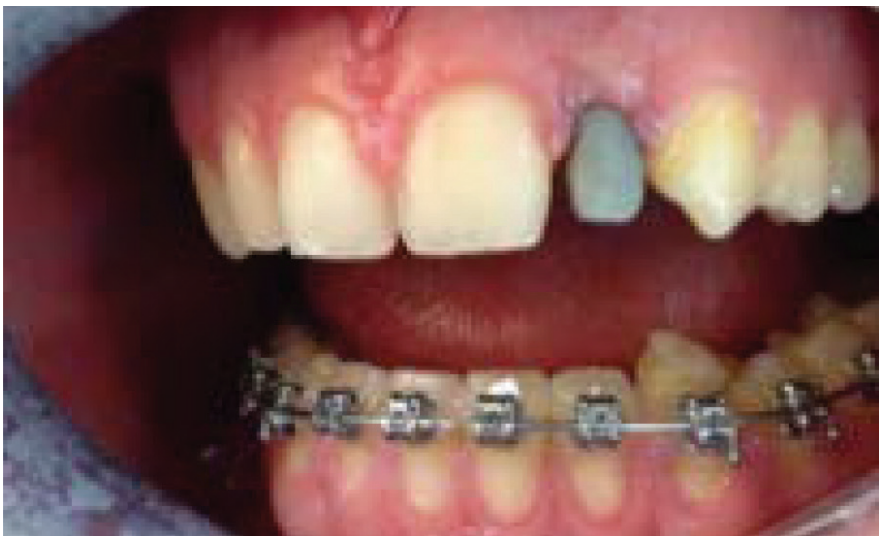

Resim 7: Metal prova

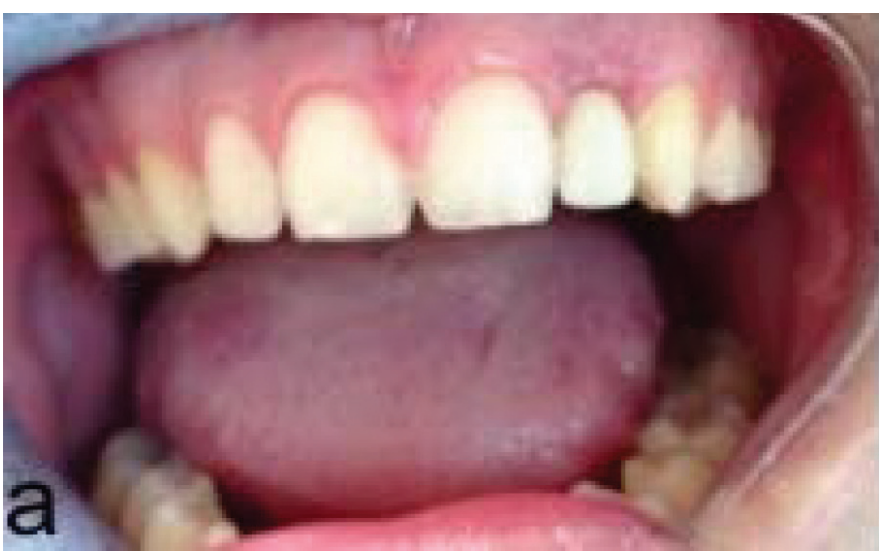

Resim 8 a: Final restorasyon

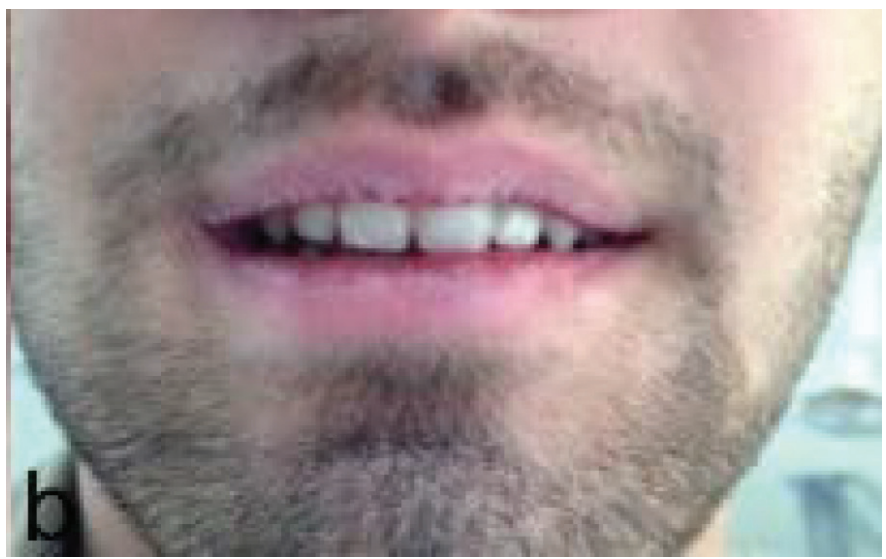

Resim 8 b: Final restorasyon

\section{TARTIŞMA}

Hastanın orta hattında kaymaya sebep olan lateral kesici eksikliği, hastanın görünümünde ve gülüşünde belirgin bir asimetriye sebep olur. ${ }^{6}$ Daimi dişlerin travmaya bağlı erken kaybedildiği veya konjenital olarak eksik olduğu durumlar ortodontik, protetik ve implant tedavisi ile kombine olarak düzeltilebilir. Günümüzde, implant tedavisi diş eksikliklerinin tedavi seçeneklerinin başında gelmektedir ve konjenital diş eksikliklerinde de başarı ile uygulanmaktadır. Tedavi planlamasının temel amacı bireyin optimum estetik ve fonksiyon intiyaçlarını karşılamaya yönelik olmalıdır. Bu multidisipliner yaklaşım ortodonti ve implant tedavisini içerdiğinde uzun soluklu bir tedaviyi gerektirir.

Implant tedavisinde genel konsept implant yerleştirildikten en az 3 ay sonra bir restorasyonun yapılmasıdır. Ancak, implant tasarımı ve yüzey özelliklerindeki gelişmeler bu sürelerin kısalabileceğini hatta hemen geçici veya daimi bir restorasyon yapılabileceğini göstermiştir. Yapılan çalışmalar hemen yüklemenin hastanın yaşam kalitesini arttırarak olumlu etki yapabileceğini bildirmişlerdir.7

Günümüzde hemen yüklenen implantlarla geleneksel yüklenen implantların başarı oranlarının benzer olduğu gösterilmiştir. ${ }^{8}$

Estetik bölgeye uygulanan implant tedavilerinde en büyük sorun dişeti estetiğinin sağlanamamasıdır. Kemik ile birlikte papilin de çekilmesi estetik olmayan bir görüntüye sebep olur. Bu çekilme cerrahi öncesi gerçekleşmiş olabileceği gibi yapılan insizyona ve flep tasarımına bağlı olarak cerrahi sonrasında da gerçekleşebilir. Cerrahi sonrasında yumuşak doku kaybını önlemek için minimal insizyon ile flap tasarımı önerilmektedir. 9,10 Gomez ve ark. ${ }^{4}$ yaptıkları çalışmada papil koruyuculu insizyon ile yerleştirilen implantlardaki marjinal kemik kaybı ve papil kaybının daha az olduğunu gözlemlemişlerdir. Estetik bölgeye uygulan implantların hemen yüklenmesi, hastaya hemen estetik ve fonksiyon kazandırdığı gibi geçici bir restorasyon ile zaman içinde dişeti şekillendirilerek final pembe estetik sağlanmış olur.

\section{SONUÇ}

Konjenital lateral eksikliği multidisipliner bir planlama ile başarılı bir şekilde tedavi edilebilmektedir. Ayrıca papil koruyuculu insizyon ile implantın yerleştirilmesi ve hemen geçici bir kron ile yüklenmesi final yumuşak doku estetiğini olumlu yönde etkilemektedir.

\section{KAYNAKLAR}

1. Ward $\mathrm{DH}$. Proportional smile design using the recurring esthetic dental (red) proportion. Dent Clin North Am 2001; 45: 143-154.

2. Rosa M. \& Zachrisson BU. Integrating space closure 
and esthetic dentistry in patients with missing maxillary lateral incisors. J Clin Orthod 2007; 41: 563-573.

3. Balshi TJ. Osseointegration and orthodontics: modern treatment for congenitally missing teeth. Int $\mathrm{J}$ Periodontics Restorative Dent 1993; 13: 494-505.

4. Gomez-Roman G. Influence of flap design on peri-implant interproximal crestal bone loss around single-tooth implants. Int J Oral Maxillofac Implants 2001; 16: 61-67. 5. Ganeles J \& Wismeijer D. Early and immediately restored and loaded dental implants for single-tooth and partial-arch applications. Int $\mathrm{J}$ Oral Maxillofac Implants 2004; 19 Suppl: 92-102.

6. Thomas B, Joseph RM \& Sholapurkar A. Management of a patient with congenitally missing lateral incisor: a multidisciplinary team approach. Rev. clin. pesq. odontol. 2009; 5: 293-299.

7. Bağrıvatan $G$, Çelik $M$, Çilingir A \& Bayrakdar G. İmmediyat implant yükleme protokolü: güncel yaklaşımlar. Atatürk Üniversitesi Diş Hekimliği Fakültesi Dergisi 2014; 9: 169-174.

8. Esposito M, Grusovin MG, Maghaireh H \& Worthington $H V$. Interventions for replacing missing teeth: different times for loading dental implants. Cochrane database Syst Rev 2013; 28(3): CD003878.

9. Nemcovsky CE. \& Artzi Z. Split palatal flap. I. A surgical approach for primary soft tissue healing in ridge augmentation procedures: technique and clinical results. Int J Periodontics Restorative Dent 1999; 19: 175-181.

10. Al-Sabbagh M. Implants in the Esthetic Zone. Dent Clin North Am 2006; 50: 391-407. 